\title{
INTEGRATED TECHNOLOGY OF DATA REMOTE SENSING AND GIS TECHNIQUES ASSESS THE LAND USE AND LAND COVER CHANGES OF MADURAI CITY BETWEEN THE YEAR 2003-2013
}

\author{
R. Srinivasan ${ }^{1 *}$, Dr.M.Mohamed Sathik ${ }^{2}$ \\ *IAssistant professor Department of Computer science S.LS.MAVMM.AV.College Madurai-Tamilnadu. \\ ${ }^{2}$ Principal Sadakathulla Appa College,Rahmath Nagar Tirunelveli-Tamil nadu
}

*Corresponding Author: -

\begin{abstract}
: -
The present study focuses on the nature and pattern of urban expansion of Madurai city over its surrounding region during the period from 2003 to 2013. Based on its proximity to the Madurai city, Preparation of various thematic data such Land use and Land cover using Land sat data. Create a land use land cover map from satellite imagery using supervised classification. Find out the areas from the classified data. The study is based on secondary data, the satellite imagery has downloaded from GLCF (Global Land Cover Facility) web site, for the study area (path101 row 67), the downloaded imagery subset using Imagery software to clip the study area. The clipped satellite imagery has used to prepare the land use and land cover map using supervised classification.
\end{abstract}

Keywords: - Land use, Land Cover, Landsat data, Satellite imagery

\section{(c) $($ ) (1)}




\section{INTRODUCTION}

Land use is obviously constrained by environmental factors such as soil characteristics, climate, topography, and vegetation. But it also reflects the importance of land as a key and finite resource for most human activities including agriculture, industry, forestry, energy production, settlement, recreation, and water catchment and storage. Land is a fundamental factor of production, and through much of the course of human history, it has been tightly coupled with economic growth. Often improper Land use is causing various forms of environmental degradation. For sustainable utilization of the land ecosystems, it is essential to know the natural characteristics, extent and location, its quality, productivity, suitability and limitations of various. Land use is a product of interactions between a society's cultural background, state, and its physical needs on the one hand, and the natural potential of land on the other (Balak Ram and Kolarkar 1993). In order to improve the economic condition of the area without further deteriorating the bio environment, every bit of the available land has to be used in the most rational way.

\subsection{Aim and Objectives}

1. To identify the land use/land cover map of Madurai for year 2003,2013

2. To study and compare the demographic change between the above years

3. To spatially map the residential Development of Madurai city.

\subsection{Date Base}

The following topographic maps are collected form Survey of India (SOI), Bangalore. No. 58K/1 on 1:50,000 Scale 1)Madurai Corporation Map 1:16,000 Scale

2)Madurai Corporation Zone and Ward details The following Remote sensing data collected from National Remote Sensing Agency (NRSA), Hyderabad.

\section{Year 2003 data}

Satellite: IRS 1D P6 LISS 1V MX

Path and row : :101-067

Date of Acquisition: $28^{\text {th }}$ March 2003

Maanagar (City of Jasmine) and Athens of the East. It is the cultural capital of Tamil Nadu. It is a city in the Indian state of Tamil Nadu and is a municipal corporation situated on the banks of the River Vaigai in Madurai district. The city is referred as the Temple city. With a city population of 1,108,755 according to the 2004 estimation, it is the administrative capital of Madurai district.Madurai city has an area of $52 \mathrm{~km}^{2}$, within an urban area now extending over as much as 130 $\mathrm{km}^{2}$, and it is located at [show location on an interactive map $9^{\circ} 56^{\prime} \mathrm{N} 78^{\circ} 07^{\prime} \mathrm{E} / 9.93^{\circ} \mathrm{N} 78.12^{\circ} \mathrm{E} / 9.93 ; 78.12$. It has an average elevation of 101 meters above mean sea level. Paration of digital geological data from Geological survey of India (GSI) for the study area. Preparation of various thematic data such Land use and Land cover using Landsat data.Create a land use land cover map from satellite imagery using supervised classification.Find out the areas from the classified data. The study is based on secondary data, the satellite imagery has downloaded Satellite: IRS 1D P6 LISS 1V MX Path and row: $101-067$, the downloaded imagery subset using Imagery software to clip the study area. The clipped satellite imagery has used to prepare the land use and land cover map using supervised classification. The land use and land cover map clearly shows that area of Bulit up land is higher than others. bio environment, every bit of the available land has to be used in the most rational way.

Figure:1. Madurai city study area

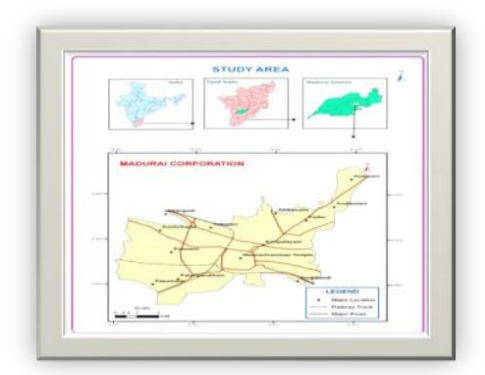

Figure:2. Madurai city satellite imagery

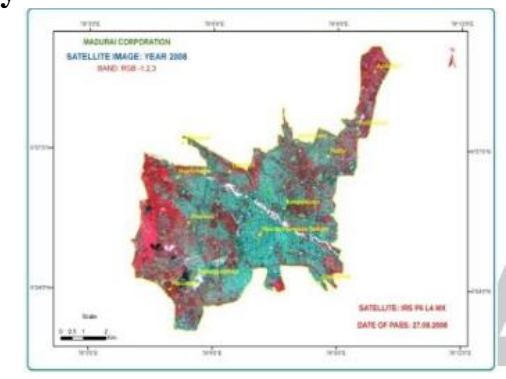




\section{Methodology}

The study is based on secondary data, the satellite imagery has downloaded. The clipped satellite imagery has used to prepare the land use and land cover map using supervised classification.

\section{Land sat}

7 Imagery The spectral resolution of each of the 7 bands, plus the panchromatic band, are summarized in the following table, along with a description of the spatial resolution and the primary use of data

\subsection{Band 1}

The spectral response of Band 1 is in the visible portion of the electromagnetic spectrum that corresponds with bluegreen light. Energy at this portion of the electromagnetic spectrum is easily scattered by particles in the atmosphere, often giving images in this band a hazy appearance. This band is capable of being transmitted through water and is especially sensitive to particles suspended in water (such as sediments and algae). Data from this band can be used with bands 2 and 3 to create "true" color composite images, which most closely approximate how the scene would appear to the human eye.

\subsection{Band 2}

The spectral response of Band 2 is in the visible portion of the electromagnetic spectrum that corresponds with green light. It can be used with bands 1 and 3 to create "true" color composite images.

\subsection{Band 3}

The spectral response of Band 3 is in the visible portion of the electromagnetic spectrum that corresponds with red light. It is also one of the three component bands used to create "true" color composite images.

\subsection{Band 4}

The spectral response of Band 4 is in the Near Infrared (NIR) portion of the electromagnetic spectrum. This form of infrared sits just outside the visible red-light portion of the electromagnetic spectrum. This form of radiation is reflected to a high degree of leafy vegetation since chlorophyll (the green pigment in green vegetation) reflects much of the NIR that reaches it (it has a high

albedo in this band)

\subsection{Band 5}

The spectral response of Band 5 is in the Middle Infrared (Mid-IR) portion of the electromagnetic spectrum. This portion of the spectrum is sensitive to variations in water content in both leafy vegetation and soil moisture. This band allows an observer to distinguishes between clouds (which appear dark) and bright snow covr (which appear light). Sensors in this band also respond to variations in ferric iron $(\mathrm{Fe} 2 \mathrm{O} 3)$ in rocks and soils, showing higher reflectance as iron content increases. This allows one to use these data to determine mineral content and soil types from space

\subsection{Band 6}

The spectral response of Band 6 is in the Thermal Infrared portion of the electromagnetic spectrum. Thermal infrared is radiation that is detected as heat energy, therefore the thermal Band 6 on the ETM+ sensor can distinguish temperature difference of about 0.6 Celsius, which allows it to detect relatively small differences in land and water surface temperatures. This makes the thermal IR band useful for a variety of purposes. For example, using band 6 data, researchers can discriminate among rock types whose thermal properties show differences in temperature near the surface. This assists researchers in creating geologic mapping of land surfaces from space. This data supports agricultural and mineral exploration efforts. ETM Band 6 data can detect changes in ground temperature due to moisture variations, assisting in drought planning, flood forecasting, and agricultural assessment. The cooling effect of water evaporating from vegetation can be detected, assisting in efforts to map land use characteristics of a region.

\subsection{Band 7}

Spectral response of Band 7 is in the Middle Infrared (Mid-IR) portion of the electromagnetic spectrum.

This portion of the electromagnetic spectrum is sensitive to moisture and thus responds to the moisture contents in soils and vegetation. The sensitivity to moisture contents is suited to detecting certain water-loving minerals, such as clays, in geologic settings. This band is also useful in detecting moisture levels in leafy vegetation, which can change under certain environmental conditions (e.g. drought, pollution, insect infestation) and thus provides a means to monitor productivity and identify agricultural areas that are under stress.

\subsubsection{Panchromatic}

0.52 to 0.90 pedometers black and white sensor with a $15 \mathrm{~m}$ spatial resolution. The higher resolution of this data assists land-use researchers by making identification of smaller objects easier. Items smaller than $30 \mathrm{~m}$ will appear fuzzy or illdefined in the $30 \mathrm{~m}$ bands of the ETM+. The $15 \mathrm{~m}$ resolution of the panchromatic band will allow researchers to make better determinations of land use and will assist in producing accurate land use maps. 


\section{TABLE .1.LAND USE 2003 MADURAI CITY}

\section{LAND USE 2003 MAP MADURAI CITY}

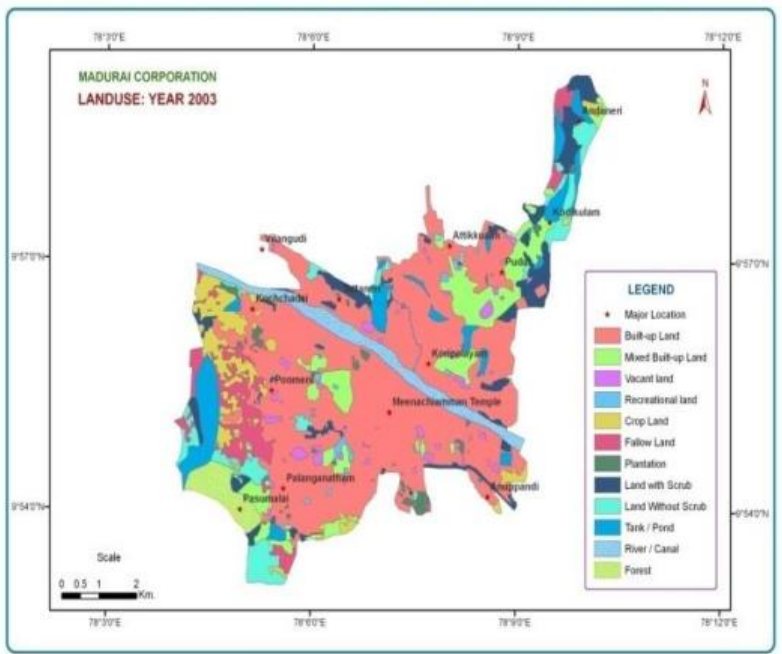

Figure:3 Landuse year 2003 Madurai city

\begin{tabular}{|c|c|l|c|c|}
\hline SL.N & LAvorsz & LANDUSE NAME & NO. OF & AREA IN \\
\hline 0 & FREQUENCY & SQ.KM \\
\hline 1 & 100 & Built-up Land & 7 & 27.96 \\
\hline 2 & 200 & Mixed Built-up Land & 24 & 4.98 \\
\hline 3 & 300 & Vacant land & 54 & 1.05 \\
\hline 4 & 400 & Recreational land & 13 & 0.30 \\
\hline 5 & 500 & Crop Land & 32 & 2.97 \\
\hline 6 & 600 & Fallow Land & 25 & 2.79 \\
\hline 7 & 700 & Plantation & 26 & 0.70 \\
\hline 8 & 800 & Land with Scrub & 39 & 3.77 \\
\hline 9 & 900 & Land Without Scrub & 21 & 2.91 \\
\hline 10 & 1000 & Tank/ Pond & 19 & 3.49 \\
\hline ap\&i-1 & 1100 & River/ Canal & 24 & 2.41 \\
\hline 12 & 1200 & Forest & 1 & 1.33 \\
\hline
\end{tabular}

Figure:4 LANDUSE -YEAR 2013

\section{LANDUSE - YEAR 2013}

\section{CHANGE DETECTION ANALYSIS:}

Change detection is the use of remotely sensed imagery of a single region, acquired on at least two dates, to identify changes that might have occurred in the interval between the two dates. Those two dates can be years apart, for example to track changes in urbanization, or days apart, for example to track changes from a volcanic eruption. Change detection has been applied to examine effects such as land use changes caused by urban and suburban growth, effects of natural disasters (such as floods, forest and range fires), and impacts of insect infestations upon forest cover, for example. Change detection requires application of algorithms that are specifically designed to detect meaningful changes in the context of false alarms - ostensible changes that are, in reality, simply artifacts of the imaging process. A critical prerequisite for application of change detection by remote sensing is the identification of suitable pairs of images representing the same region. The analyst must assure that (1) the two images register (that they match exactly when superimposed), (2) that they were acquired during the same season, especially if use to track changes in vegetation, and (3) that there are no significant atmospheric effects. In brief, the two images must be compatible in every respect-- scale, geometry, resolution - otherwise the change detection algorithm will interpret incidental differences in image characteristics as changes on the landscape. There has been much research devoted to evaluating alternative change detection algorithms. A basic distinction between pre-classification and post-classification comparisons captures a primary division in the natures of the approach. Post-classification change detection defines changes by comparing pixels in a pair of classified images (in 
which pixels have already been assigned to classes). Post classification change detection typically reports changes as a summary of the "from-to" changes of categories between the two dates. Pre-classification change detection examines differences in two images prior to any classification process. Pre-classification algorithms typically permit the analyst to set thresholds for the magnitude of changes to be detected and highlighted. This tutorial will introduce a simple procedure using ArcGIS Image Analysis for preclassification change detection - other approaches are available for the more experienced student, and to examine In GIS, map overlay /intersection operations were used to bring out the changes occurred in the land use/land cover

\begin{tabular}{|c|c|c|c|c|}
\hline o & LANDUSE NAME & 2003 & 2013 & $\begin{array}{l}\text { Area change } \\
\text { in percentage }\end{array}$ \\
\hline 1 & Built-up Land & 27.96 & 29.79 & $+18 \%$ \\
\hline 2 & $\begin{array}{l}\text { Mired Built-up } \\
\text { Land }\end{array}$ & 4.98 & 4.46 & $-52 \%$ \\
\hline 3 & Vacant land & 1.05 & 0.80 & $-25 \%$ \\
\hline 4 & Recreational land & 0.30 & 0.27 & $-0.3 \%$ \\
\hline 5 & Crop Land & 2.97 & 4.39 & $+14.2 \%$ \\
\hline 6 & Fallow Land & 2.79 & 0.47 & $-2.3 \%$ \\
\hline 7 & Plantation & 0.70 & 0.57 & $-13 \%$ \\
\hline 8 & Land with Scrub & 3.77 & 4.91 & $1.14 \%$ \\
\hline 9 & $\begin{array}{l}\text { Land Without } \\
\text { Scrub }\end{array}$ & 2.91 & 1.75 & $-1.16 \%$ \\
\hline $\begin{array}{l}1 \\
0\end{array}$ & Tank / Pond & 3.49 & 3.49 & $0 \%$ \\
\hline 1 & River / Canal & 2.41 & 2.41 & $0 \%$ \\
\hline 2 & Forest & 1.33 & 1.33 & $0 \%$ \\
\hline
\end{tabular}

Table : 3 change Detection analysis yr 2003-2013mdu.

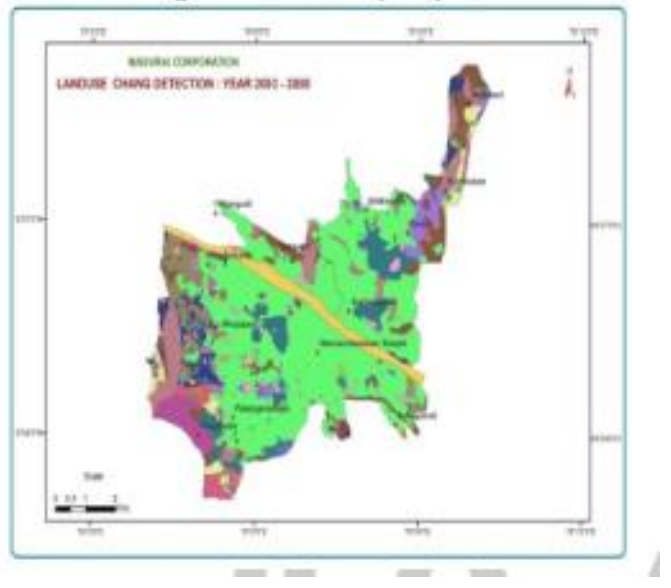

\section{Conclusion}

The urban area of Madurai city has increased tremendously within the 2003-2013(10) years. This resulted from ruralurban migration. Madurai is one of the most developing cities in Tamilnadu, after Chennai. Education institutions, industries, and factories etc are located and upcoming here. As a result, rural-urban migration has been characterizing in Madurai city. The overall percentage increased during the period of 5 years about $18 \%, 14.2 \%$, and $1.14 \%$. built-up land, Land with Scrub Sett, Corp land Comm. \& Industrial activity and Airport respectively. There has been decrease in the mixedbulit up land,vacand land,52\%,25\% and 13\%.water body and River with no change respectively. 
The results of this study were based on Image classification and its interpretation. The mapping of the urban development of Madurai town shows the development of urban lands had brought changes in other part of the city as well. The interpretation of multi-date satellite helped in the preparation of urban changes map of the study area. The decrease in agricultural/Scrub area is due to conversion of urban land use or discontinuation of agricultural lands. The Barren land has been increasing as cultivable land is left with discontinuation of cultivation due to lack of irrigation facility and seasonal variations are made them to be available as such. Similar studies can be under taken for other major cities also to estimate to make necessary arrangement to plan accordingly to preserve the natural environment.

\section{References}

[1].Carter. H, 1995, The study of Urban Geography, Arnold publisher, London.

[2].Cheng. J, and Maser, 2003, urban growth pattern modeling: a case study of Wuhan city,PR China. "Landscape and Urban Planning", Vol. 62, pp 199217.

[3].Epstein. J, K. Payne, and E. Kramer, 2002, Techniques for mapping suburban sprawl.'Photogrammetric Engineering and Remote Sensing", Vol. 63(9), pp $913-918$

[4].Fan. F, Yawing, et.al., 2009, Evaluating the Temporal and Spatial Urban Expansion Patterns of Guangzhou from 1979 to 2003 by Remote Sensing and GIS Methods, "International Journal of Geographical Information Science", Vol. 23(11), pp 1371-1388

[5].Hoyle. B.S, 1973, Geographical Readings Transport and Development, The Macmillan Press Ltd, London.

[6].Huang. B, Li Zhang and Bo Wu, 2009, Spatiotemporal analysis of rural-urban land conversion, "International Journal of Geographical Information Science", Vol. 23(3), pp 379-398

[7].Jensen. J.R, and D.L. Toll, 1982, Detecting residential landuse development at the urbanfringe, "Photogrammetric Engineering and Remote Sensing", Vol. 48(4), pp 629643.

[8].Mahdibeigi. H, M. Mahdavi and A. Alihosseini, 2010, Transforming large villages intosmall towns and studying their role in rural development through Network Analysis Methodology: Rural district of Southern Behnam Arab (Javad Abad zone from the regionof Varamin), "Journal of Geography and Regional Planning", Vol. 3(6), pp 158168.

[9].Siyuan. W, L. Jingshi and Y. Cunjian, 2007, Temporal change in the landscape erosion pattern in the Yellow River Basin, China, "International Journal of Geographical Information Science”, Vol. 21(10), pp 1077-1092.

[10]. Sudhira.H.S, T.V. Ramachandra, K.S.Jagadish, 2004, Urban sprawl: metrics, dynamics and modelling using GIS, "International Journal of Applied Earth Observation and Geoinformation", Vol. 5, pp 29-391.

[11]. Anderson, James R., 1971, Land use classification schemes used in selected recent geographic applications of remote sensing: Photogramm.Eng, v. 37, no. 4, p. 379-387.

[12]. Anderson, James R., Hardy, Ernest E., and Roach, John T., 1972, A land-use classification system for use with remote-sensor data: U.S. Geol. Survey Cire. 671, 16 p., refs.

[13]. Bhat M .M and Shah A R. 2011; Agricultural Land Use and Cropping Pattern in Jammu and Kashmir, Research Journal of Agricultural Sciences, 2(3): 710-712.

[14]. Chakraborty K, Joshi P.K, Sharma K. K M 2009; Land use / Land cover Dynamics in Umngot Watershed of Meghalaya using Geospatial tools; .Journal of Indian Science of Remote Sensing. 37:99-106.

[15]. Daniel Ayalew Mengistu and Ayobami T. Salami 2007; Application of remote sensing and GIS inland use/land cover mapping and change detection in a part of south western Nigeria; African Journal of Environmental Science and Technology Vol. 1 (5), pp. 099-109, December,

[16]. Gautam N.C. and Raghavswamy V 2004; Land Use/Land Cover and Management Practices in India; BSP, viii, 310 p, maps, tables, figs, ISBN: 8178000520.

[17]. Golam Rasul2009; Ecosystem services and agricultural land-use practices: a case study of the Chittagong Hill Tracts of Bangladesh, Sustainability: Science, Practice, \& Policy, Fall | Volume 5 | Issue 2.

[18]. Kaul M, Dadhwal V.K, Mohren G.M.J2009; Land use change and net C flux in Indian forests; Forest Ecology and Management 258 100-108, Indian Institute of Remote Sensing (IIRS), 4 Kalidas Road, Dehradun, UA 248001, India.

[19]. Krishnamurthy Y.V.N., Dy. Head, RRSSC, Nagpur and Shri S.Adiga, Director, NNRMS-RRSSC, ISRO Hqs, Bangalore Nationwide Land Use/Land Cover Mapping Using Indian Remote Sensing Satellite Data-a Digital Mapping Approach.

[20]. Wani M.H, Baba S.H and Shahid Yousuf 2009; Land-use Dynamics in Jammu and Kashmir. Agricultural Economics Research Review Vol. 22, pp 145-154.

[21]. National Wetland Atlas Jammu and Kashmir, Sponsored by Ministry of Environment and Forests, Government of India. AC/RESA/AFEG/NWIA/ATLAS/16/2010. 